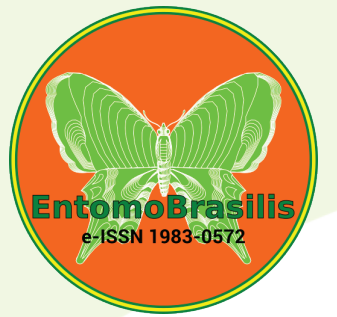

\title{
Briononnies and Behavior/BBiononnia \& Connporttanentio Óleo essencial de citronela (Poaceae) e seus componentes para controle do brasileirinho (Coleoptera: Chrysomelidae) em olerícolas
}

\author{
Julianne Milléo ${ }^{\bowtie}$, Carlos Henrique Antunes, Elis Borges Pettres, Ricardo Antonio Ayub \& Paulo Vitor Farago
}

Universidade Estadual de Ponta Grossa.

\section{EntomoBrasilis 12 (1): 06-10 (2019)}

\begin{abstract}
Resumo. Este estudo teve como objetivo obter uma formulação atrativa à base de óleo de citronela e seus componentes voláteis para captura de Diabrotica speciosa (Germar). Três experimentos sequenciais foram realizados em culturas de abobrinha ou pepino. Os insetos foram coletados por armadilhas de garrafa PET com três aberturas laterais, contendo um volume de $200 \mathrm{ml}$ de cada formulação, suspensas a $10 \mathrm{~cm}$ do nível do solo numa área experimental de $30 \mathrm{~m}^{2}$. No primeiro experimento foram testados óleo de citronela em $1,2 \mathrm{e} 4 \%$. No segundo investigou-se também a ação de citronelal, citronelol e geraniol a 1\%. E, o citronelol a o,5, 1 e $2 \%$ foi testado no terceiro experimento. Como resultado observou-se que a formulação contendo citronelol a $0,5 \%$ foi estatisticamente superior às demais. Outros insetos foram capturados pelas armadilhas como coleópteros Diabrotica viridula (Fabricius) e Astylus variegatus (Germar), e também exemplares de Diptera, Hemiptera e Hymenoptera. Considerando a alta demanda por alimentos orgânicos e da preocupação com o ambiente e a saúde, a emulsão a base de citronelol em o,5\% cumpre adequadamente o seu objetivo, garantindo uma boa capacidade atrativa para $D$. speciosa. Esta formulação pode ser usada paralelamente com outros métodos alternativos para reduzir a presença desse inseto nas culturas.
\end{abstract}

Palavras-chave: Citronelal; citronelol; controle de insetos-praga; Diabrotica speciosa; geraniol.

\section{Citronella (Poaceae) essential oil and its components for the control of brasileirinho (Coleoptera: Chrysomelidae) in vegetable crops}

\begin{abstract}
The present study aimed to get an attractive formulation of oil-based citronella and its volatile components to capture Diabrotica speciosa (Germar). Three sequential experiments were performed in zucchini or cucumber crops. The insects were collected in PET bottle traps with three lateral apertures, containing a volume of $200 \mathrm{ml}$ of each formulation, suspended $10 \mathrm{~cm}$ above the ground level in an experimental area of $30 \mathrm{~m}^{2}$. In the first experiment citronella essential oil was tested at 1, 2 and 4\%. In the second experiment the action of citronellal, citronellol and geraniol at 1\% were investigated. Furthermore, citronellol at $0.5,1$ and $2 \%$ has been tested in the third experiment. As a result it was observed that the formulation containing $0.5 \%$ citronellol was statistically higher than the other tested formulations. Other insects were captured by the traps as the beetles of Diabrotica viridula (Fabricius) and Astylus variegates (Germar), and also copies of Diptera, Hemiptera and Hymenoptera. Considering the high demand for organic food, and concern for the environment and health, the citronellol emulsion at $0.5 \%$ adequately fulfilled its goal, ensuring a good attractive capacity for $D$. speciosa. This formulation can be used simultaneously with other alternative methods to reduce the presence of such insects in crops.
\end{abstract}

Keywords: Citronellal; citronellol; Diabrotica speciosa; geraniol; insect pest control.

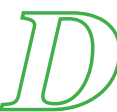
iabrotica

speciosa

(Germar) Chrysomelidae) conhecida popularmente brasileirinho, vaquinha ou patriota, é comumente encontrada nos países sul-americanos e na quase totalidade dos estados brasileiros, sendo considerada uma praga polífaga (Milanez et al. 1999). No Brasil, D. speciosa causa danos em milho, feijoeiro, soja, amendoim, girassol, batata e cucurbitáceas (Milanez \& PARRA 2000; Gallo et al. 2002). O adulto alimenta-se de folhas, brotações novas, vagens, frutos, causando danos em diferentes culturas, seja pelo efeito direto, em razão da injúria causada na planta, ou indiretamente, como agente transmissor de patógenos, especialmente vírus. As larvas, que são de hábito subterrâneo, podem danificar as raízes e tubérculos de plantas (Ávila et al. 2002).

Ao se alimentar de folhas, as vaquinhas reduzem a área fotossintética das plantas (Leite et al. 1993), sendo que novos estudos mostraram que apenas dois destes insetos por planta provocam desfolha de até $16 \%$ em 24 horas (Silva et al. 2003).

Utilizam-se os inseticidas para a redução desses coleópteros nas culturas. Entretanto, essas substâncias químicas sintéticas são
Edited by:

William Costa Rodrigues

Article History:

Received: $14 . i v .2018$

Accepted: 25.iii.2019
Corresponding author:

Julianne Milléo

jimilleo@hotmail.com

(Tttp://orcid.org/0000-0003-4817-2461
Funding agencies:

$\Delta$ Without funding declared 
tóxicas e perigosas à saúde. Métodos de controle alternativo de insetos-praga sem que haja aplicação de agrotóxicos têm sido testados em consequência da crescente utilização de alimentos orgânicos, e também com a preocupação com o meio ambiente e a saúde humana (VEndramim \& CASTIGLIONI 2000). Em termos de agricultura orgânica são empregados produtos alternativos, como raiz de taiuiá (STÜPp et al. 2006), óleo de nim (SEFFrin et al. 2008), extratos aquosos de fumo, pitangueira, cinamomo e alho (MACHADO et al. 2007).

SEDORKo et al. (2010) ao realizarem testes com oito atrativos preparados a partir de óleos essenciais comerciais, com intuito de propor uma alternativa para o controle de moscas-da-fruta (Diptera: Tephritidae) notaram que, dos 422 insetos capturados no experimento, $21 \%$ eram da espécie $D$. speciosa, atraídas por citronela (Cymbopogon sp).

Acitronela pertencente à família Poaceae, é uma planta aromática largamente empregada na formulação de repelentes para insetos, e mais recentemente na atividade bactericida fitopatogênica, como provado por Costa et al. (2008). O óleo essencial extraído de suas folhas possui mais de 80 componentes, sendo que os mais representativos são: o citronelal $28 \%$, o nerol $31 \%$ e a pulegona $20 \%$, e quantidades menores de geraniol e citronelol (CosTA et al. 2008), sendo este último um dos principais responsáveis pela propriedade aromatizante da planta.

Assim, como não existe, até o presente momento, uma estratégia orgânica ideal para reduzir expressivamente o número dos coleópteros, o uso do óleo essencial de citronela pode ser empregado como um produto natural com eficácia ao controle de D. speciosa.

Portanto, esse estudo teve como objetivos: descrever a formulação baseada em componentes voláteis do óleo essencial de citronela com tensoativos emulsionantes; relatar os resultados dos experimentos conduzidos no campo para investigar a aplicação dessa nova formulação na atração e, consequente redução, de $D$. speciosa em hortas orgânicas.

\section{MATERIAIS E MÉTODOS}

Os experimentos foram realizados em hortas orgânicas no município de Ponta Grossa/PR. Para coleta dos insetos foram utilizadas armadilhas feitas com garrafas PET com três aberturas laterais (adaptadas de Aguiar-MENEZes et al. 2006). Estas armadilhas ficaram suspensas a cerca de $10 \mathrm{~cm}$ do solo por suportes de ferro e distribuídas aleatoriamente em $30 \mathrm{~m}^{2}$ na área experimental.

Para que ocorra a eliminação do inseto, é necessário que o coleóptero tenha contanto com o meio aquoso, para ser apreendido pelo mesmo e, consequentemente ocorra a sua morte. Porém, o óleo essencial de citronela e seus principais componentes são monoterpenos de baixa solubilidade em água, o que gera a necessidade do desenvolvimento de uma formulação especializada para que esse composto volátil permaneça estável e mantenha a atividade na atração dos crisomelídeos.

Cada armadilha continha $200 \mathrm{~mL}$ de cada formulação dispersa nesse meio. Além destas, duas outras armadilhas foram utilizadas como testemunha, uma apenas com água purificada e a outra somente com os tensoativos diluídos em água (aqui denominado controle negativo).

Foram realizadas quatro coletas para avaliar a eficiência dos atrativos:

Período 1, de 23/03 a 20/04/2011, em plantio de abobrinha (Cucurbita pepo L.) e de pepino (Cucumis sativus L.), em cada área foram montadas cinco armadilhas que continham, respectivamente, água, controle negativo e formulação com o óleo de citronela 1,2 e $4 \%$.

Período 2, de03/05a 07/06/2013, plantio de abobrinha, nas seis armadilhas instaladas foram testados os seguintes componentes: água, controle negativo, formulação de óleo de citronela $1 \%$, formulação de citronelal 1\%, formulação de citronelol 1\% e formulação de geraniol $1 \%$.

Período 3, de 21/10 a 25/11/2013, plantio de abobrinha com seis armadilhas que continham respectivamente: água, controle negativo, formulação de citronela 1\% e formulação de citronelol o,5, 1 e $2 \%$.

No dia da coleta e substituição das formulações, foi realizado rodízio na disposição das armadilhas, de modo que todas as soluções testadas foram colocadas em todos os pontos da área pelo mesmo espaço de tempo.

O material coletado foi recolhido semanalmente e o conteúdo lavado com água. Os insetos foram acondicionados em potes plásticos etiquetados com os dados da coleta, contendo álcool $70 \%$. Posteriormente, estes insetos foram levados ao laboratório para identificação, triagem dos exemplares de $D$. speciosa e contagem. Os resultados foram registrados em planilhas do Excel, para análise estatística.

O delineamento experimental foi inteiramente ao acaso com cinco ou seis repetições, de acordo com o número de compostos testados. Como os dados, mesmo após transformações, não apresentaram normalidade e homogeneidade de acordo com os testes de Shapiro-Wilk (W) e Bartlett, respectivamente, foram submetidos ao teste não-paramétrico de Kruskal-Wallis, comparados a $1 \%$ de probabilidade, com pós-teste U de MannWhitney. Utilizou-se o programa estatístico Graph Pad Prism 5.01.

Descrição da formulação. A partir do óleo essencial de citronela, procurou-se formular uma emulsão do tipo óleo em água, obtendo um produto com propriedades ideais para uso em armadilhas de campo, ao mesmo tempo mantendo o meio aquoso externo necessário à morte dos insetos e estabilizando o monoterpeno responsável pelo processo atrativo, na fase interna da emulsão.

A obtenção da formulação foi feita a partir do uso de dois tensoativos emulsionantes, com o objetivo de melhor estabilizar o óleo de citronela em uma fase aquosa dispersante. Para a seleção dos tensoativos, foi adotado o critério científico que considera os valores de equilíbrio hidrofílico-lipofílico (EHL) dos mesmos. O EHLde um tensoativo é uma propriedade importante no processo de emulsificação, posto que determina o tipo de emulsão que se deseja produzir e também garante a maior estabilidade do ativo, no caso, o óleo de citronela. Além disso, a literatura demonstra que o uso de uma mistura de tensoativos produz emulsões mais estáveis do ponto de vista termodinâmico do que a utilização de um único tensoativo (GADHAVE 2014). Além disso, optou-se por tensoativos de baixo custo e que permitissem a preparação da formulação por mistura simples dos componentes, sem o uso de fontes de calor.

Dessa forma, considerando que o óleo de citronela tem um valor de equilíbrio hidrofílico-lipofílico requerido de 13 e que a porcentagem de tensoativo na formulação foi padronizada em $2 \%$, foi preparada uma mistura de mono-oleato de sorbitano (Span 80), com valor de EHL de 4,3, e de mono-oleato de sorbitano etoxilado (Tween 80), com valor de EHL de 15, na proporção de 0,37 e de 1,63\%, respectivamente, a qual garante a maior estabilidade do óleo de citronela na emulsão. Em síntese, a formulação utilizada durante os experimentos de campo do período 1 está apresentada na Tabela 1. 
Tabela 1. Formulação base para a realização dos experimentos no período 1.

\begin{tabular}{lcc}
\hline Composição*** $^{* *}$ & Concentração (\%) & Função \\
\hline Óleo de citronela* & $1-2-4^{* *}$ & Ativo para a atração dos crisomelídeos \\
Tween 80 & 1,63 & Emulsionante não-iônico de alto EHL \\
Span 80 & 0,37 & Emulsionante não-iônico de baixo EHL \\
Água purificada & q.s.p. 10o mL & Veículo \\
\hline
\end{tabular}

* Para os períodos 2 e 3, conforme descrito no texto, algumas formulações foram elaboradas a partir da substituição do óleo de citronela por um dos seus monoterpenos isolados, citronelal, citronelol e geraniol.

** Para os períodos 2 e 3, conforme detalhado no texto, o ativo para a atração da espécie $D$. speciosa foi empregado a $0,5,1$ ou $2 \%$.

*** As formulações usadas como controle negativo foram obtidas na ausência de qualquer ativo, mas contendo os tensoativos emulsionantes na proporção indicada na tabela.

\section{RESULTADOS E DISCUSSÃO}

Os resultados indicam o potencial de uso das substâncias atrativas testadas em cada um dos períodos de coleta, como pode ser observado na Tabela 2.

No primeiro período avaliado, as armadilhas com óleo essencial de citronela diluído a $1 \%$, mostraram-se mais eficientes em relação às demais formulações, tanto na cultura de abobrinha quanto na de pepino, capturando respectivamente 52,41\% e 50,81\% dos exemplares de D. speciosa. Também apresentou relevância a diluição do óleo de citronela a $2 \%$, que coletou $29,66 \%$ no plantio de abobrinha e $23,78 \%$ no plantio de pepino. A formulação a $4 \%$ atraiu respectivamente $13,10 \%$ e $19,46 \%$ dos crisomelídeos, nas mesmas culturas avaliadas (Figuras 1A e 1B). Apesar do enfoque do presente trabalho ser a $D$. speciosa, vale ressaltar que diversos insetos foram capturados pelas armadilhas. Entre outros coleópteros, destacam-se Diabrotica viridula (Fabricius) (Coleoptera: Chrysomelidae), Astylus variegatus (Germar) (Coleoptera: Melyridae); além de um grande número de dípteros, hemípteros e himenópteros, os quais ainda aguardam por identificação de especialistas.

Considerando os resultados anteriores, manteve-se a formulação de óleo de citronela a $1 \%$ e despertou-se a curiosidade em investigar se algum dos componentes voláteis desse óleo essencial poderia apresentar maior potencial atrativo para a $D$. speciosa, indicando uma possível preferência do inseto por algum componente específico. Portanto, no segundo período de coletas, foram incluídos nos testes formulações contendo citronelal, citronelol e geraniol, obtidas todas a $1 \%$. Neste experimento, o citronelol apresentou alta eficácia na atratividade, representando 66,17\% dos crisomelídeos capturados, com diferença estatística significativa em relação a todos os demais grupos em teste (Figura 2). O óleo de citronela apreendeu, em média, 17,10\% dos espécimes de brasileirinhos, valor inferior ao verificado nos experimentos do período 1 . O que indicou uma maior preferência atrativa do inseto ao componente monoterpeno isolado, o citronelol, em comparação ao conjunto de compostos voláteis presentes na formulação de óleo de citronela a $1 \%$.

Os componentes geraniol e citronelal atraíram, respectivamente, 10,41e 4,46\%, não apresentando diferença estatística significativa em relação ao controle negativo no número de exemplares capturados de $D$. speciosa, o que representou um baixo efeito atrativo.

Visando estabelecer uma formulação ideal para o uso do citronelol na atração de $D$. speciosa, com aplicação efetiva em culturas orgânicas de hortaliças, procurou-se investigar se a diferença na concentração do citronelol poderia afetar a atratividade dos crisomelídeos. No último período de coleta, a formulação de citronelol a $0,5 \%$ foi a que apresentou melhor desempenho, sendo responsável pela captura de 47,27\% dos exemplares de $D$. speciosa. Valores de 21,59; 20,91 e 7,95\% foram obtidos como porcentagens do número de insetos atraídos pelas formulações de citronelol a $1 \%$, citronelol a $2 \%$ e óleo de citronela a $1 \%$, respectivamente (Figura 3). A partir dos resultados indicados na Tabela 2, foi possível observar que a formulação contendo citronelol a $0,5 \%$ foi estatisticamente superior as demais concentrações de citronelol investigadas e ao óleo de citronela, tendo um resultado efetivo para uso no campo.

Considerando-se que a inclusão dos diferentes compostos voláteis nas armadilhas e que a proximidade entre elas pode ter interferido nos resultados, pressupõe-se que o efeito atrativo será potencializado se todas as armadilhas dispersas forem preenchidas com a formulação de citronelol a 0,5\%.

Tabela 2. Número médio ( \pm desvio padrão) de Diabrotica speciosa coletadas por armadilhas em culturas orgânicas, Ponta Grossa/PR (média).

\begin{tabular}{|c|c|c|c|c|}
\hline \multirow{3}{*}{ Formulação } & \multicolumn{4}{|c|}{ Média de exemplares de D. speciosa coletados } \\
\hline & \multicolumn{2}{|c|}{\begin{tabular}{|l|l} 
Período 1 \\
\end{tabular}} & \multirow{2}{*}{$\begin{array}{c}\text { Período } 2 \\
\text { Abobrinha } \\
\end{array}$} & \multirow{2}{*}{\begin{tabular}{|c|} 
Período 3 \\
Abobrinha
\end{tabular}} \\
\hline & Abobrinha & Pepino & & \\
\hline Água & $\mathrm{o}, \mathrm{O} \quad \mathrm{d}$ & $1,0 \pm 1,55 \mathrm{c}$ & $0,2 \pm 0,37 \mathrm{c}$ & $0,2 \pm 0,37 \mathrm{~d}$ \\
\hline Cont. negativo & $1,4 \pm 1,02 \mathrm{~cd}$ & $1,2 \pm 0,75 \mathrm{c}$ & $0,7 \pm 0,75 \mathrm{c}$ & $0,8 \pm 1,07 \mathrm{~d}$ \\
\hline Citronela $1 \%$ & $15,2 \pm 2,14 a$ & $18,8 \pm 1,33 a$ & $7,7 \pm 3,90 \mathrm{~b}$ & $3,5 \pm 1,26 \mathrm{c}$ \\
\hline Citronela 2\% & $8,6 \pm 4,67 b$ & $8,8 \pm 0,40 \mathrm{~b}$ & - & - \\
\hline Citronela $4 \%$ & $3,8 \pm 2,14 c$ & $7,2 \pm 2,99 b$ & - & - \\
\hline Citronelal $1 \%$ & - & - & $2,0 \pm 1,63 \mathrm{bc}$ & - \\
\hline Citronelol 1\% & - & - & $\mathbf{2 9 , 7} \pm \mathbf{1 8 , 2 3} \mathbf{a}$ & $9,5 \pm 0,96 b$ \\
\hline Geraniol 1\% & - & - & $4,7 \pm 2,62 \mathrm{bc}$ & - \\
\hline Citronelol o,5 \% & - & - & - & $20,8 \pm 4,41 \mathrm{a}$ \\
\hline Citronelol 2\% & - & - & - & $9,2 \pm 1,07 \mathrm{~b}$ \\
\hline Valor H & 19,3 & 20,77 & 26,46 & 33,88 \\
\hline
\end{tabular}

Médias seguidas pela mesma letra nas colunas não diferem estatisticamente pelo teste U ao nível de $1 \%$ de probabilidade. 

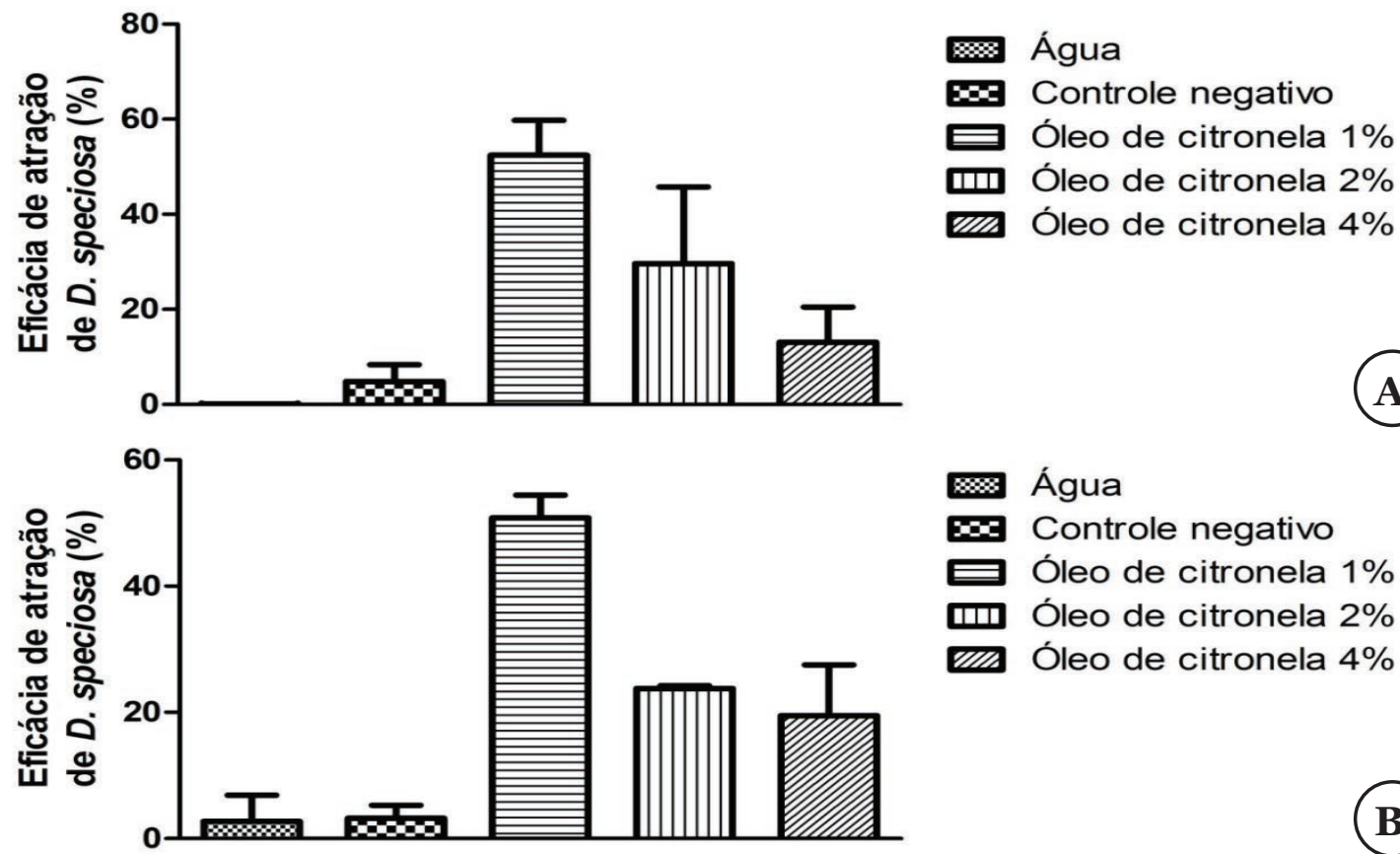

Figuras 1A e 1B. Número médio de D. speciosa coletadas no período experimental 1, por armadilhas em culturas orgânicas de abobrinha e pepino, respectivamente.

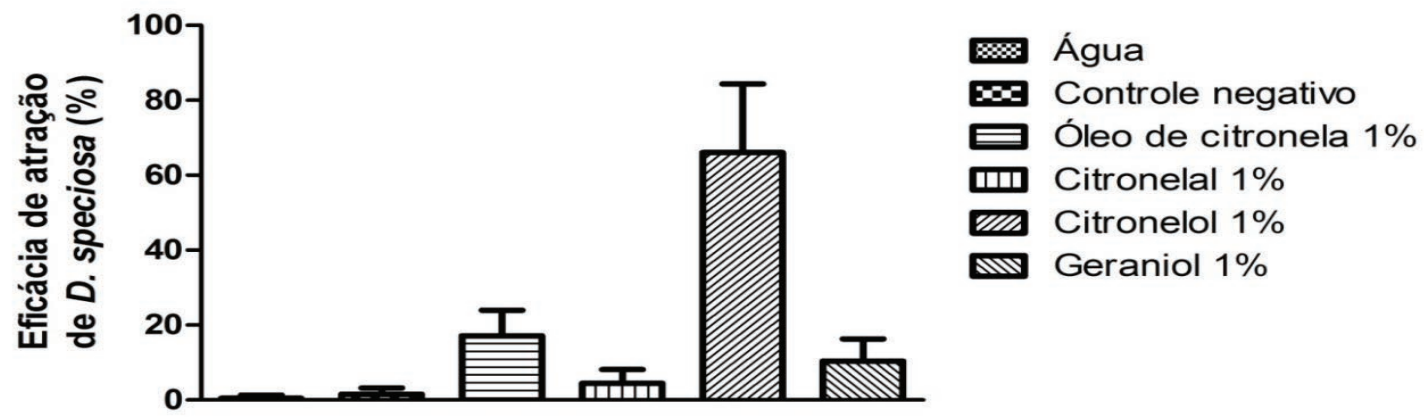

Figura 2. Número médio de D. speciosa coletadas no período experimental 2, por armadilhas em cultura orgânica de abobrinha.

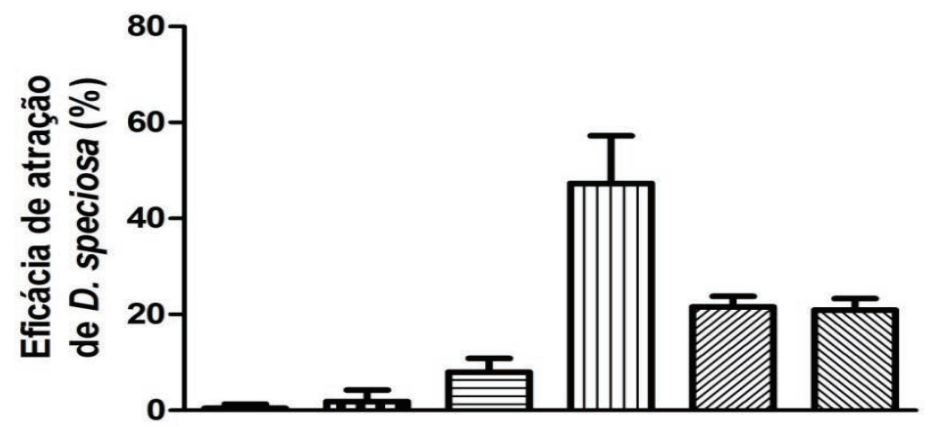

Água
Controle negativo
Onleo de citronela 1\%
Citronelol $0,5 \%$
Citronelol $1 \%$
Citronelol $2 \%$

Figura 3. Número médio de D. speciosa coletadas no período experimental 3, por armadilhas em cultura orgânica de abobrinha.

Portanto, foi possível concluir que a formulação com base no citronelol a $0,5 \%$ assegura uma boa capacidade atrativa do crisomelídeo D. speciosa.

O processo de obtenção da presente formulação ocorre de forma simples, rápida através de um processo de emulsificação a frio. Além de apresentar baixo custo por utilizar tensoativos amplamente disponíveis no mercado.

Sugere-se que a formulação seja aplicada concomitantemente com outros métodos alternativos para potencializar a redução do inseto nas culturas.

\section{AGRADECIMENTOS}

À empresa BioFragane Essências \& Fragrâncias pela doação da matéria prima utilizada nos experimentos.

\section{REFERÊNCIAS}

Aguiar-Menezes, E.L., J.F. Souza, S.A.S. Souza, M.R. Leal, J.R. Costa \& E.B. Menezes, 2006. Armadilha PET para Captura de Adultos de Moscas-das-Frutas em Pomares Comerciais e Domésticos. Seropédica: Embrapa Agrobiologia - Circular Técnica n. 16. Dez. Disponível em: < http://www.infoteca. 
cnptia.embrapa.br/bitstream/doc/623026/1/cito16.pdf> [Acesso em: 17.iv.2018].

Ávila, C.J., J.M. Milanez \& J.R.P. Parra, 2002. Previsão de ocorrência de Diabrotica speciosa utilizando-se o modelo de graus-dia de laboratório. Pesquisa Agropecuária Brasileira, 37: 427-432. DOI: https://doi.org/10.1590/s0100204X2002000400001.

Costa, C.M.G.R., M.S. Santos, H.M.M. Barros, P.F.M. Agra \& M.A.A. Farias, 2008. Óleo essencial de citronela no controle da bactéria fitopatogênica Erwinia carotovora. Revista Tecnologia \& Ciência Agropecuária, 2: 11-14.

Gadhave, A., 2014. Determination of Hydrophilic-Lipophilic Balance Value. International Journal of Science and Research, 3: $573-575$.

Gallo, D., O. Nakano, S. Silveira Neto, R.P.L. Carvalho, G.C. Baptista, E. Berti Filho, J.R.P. Parra, R.A. Zucchi, S.B. Alves, J.D. Vendramim, L.C. Marchini, J.R.S. Lopes \& C. Omoto, 2002. Entomologia Agrícola. Piracicaba: FEALQ, 920 p.

Leite, L.G., V.A. Yuki, A. Batista Filho, J.L. Castro \& N. Bortoletto, 1993. Simulação de danos provocados por insetos mastigadores nas folhas primárias do feijoeiro (Phaseolus vulgaris) através de desfolha artificial. Ecossistema, 18: 5661.

Machado, R.T., P. Rosalino, J. Rodrigues, E. Junges, L. Ribeiro, C.G. Manzoni \& S.B. Dequech, 2007. Avaliação da bioatividade de extratos vegetais sobre Diabrotica speciosa em casa de vegetação. Revista Brasileira de Agroecologia, 2: 1461-1464. Disponível em: <http://aba-agroecologia.org.br/revistas/ index.php/rbagroecologia/article/view/7010/5166>. [Acesso em: 17.iv.2018].

Milanez, J.M., J.R.P. Parra, C. Pandolfo, E.S. Pereira, A.M. Massignam \& G.X. Miranda Jr, 1999. Estimativa do número de gerações de Diabrotica speciosa (Germar, 1824), ocorrente na cultura do milho, baseado no estudo de exigências térmicas. In: XI Congresso Brasileiro de Agrometeorologia e II Reunião Latino-Americana, Florianópolis. Anais. Florianópolis: Sociedade Brasileira de Agrometeorologia, 1999. 7 p.
Milanez, J.M. \& J.R.P. Parra, 200o. Biologia e exigências térmicas de Diabrotica speciosa (Germar) (Coleoptera:Chrysomelidae) em laboratório. Anais da Sociedade Entomológica do Brasil, 29: 23-29. DOI. https://doi.org/10.1590/s0301$\underline{80592000000100003 .}$

Sedorko, D., P.E. Husch, J. Milléo, R.A. Ayub \& D.S. Nunes, 2010. Estudos com moscas-das-frutas (Diptera: Tephritidae) na Região de Ponta Grossa - PR. In: II Ciclo de Atualização Agropecuária na $33^{\mathrm{a}}$ EFAPI - Exposição Feira Agropecuária, Industrial de Ponta Grossa. Anais. Ponta Grossa: Instituto Agronômico do Paraná, 5 p.

Seffrin, R.C.A.S., E.C. Costa, L.S.D. Domingues, S.T.B. Dequech \& C.D. Sausen, 2008. Atividade inseticida de meliáceas sobre Diabrotica speciosa (Col., Chrysomelidae). Ciência Rural, 38: 1805-1809. DOI: https://doi.org/10.1590/s010384782008000700001.

Silva, A.L., V.R.S. Veloso, C.M.P. Crispim, V.C. Braz, L.P. Santos \& M.P. Carvalho, 2003. Avaliação do efeito da desfolha na cultura do feijoeiro (Phaseolus vulgaris). Pesquisa Agropecuária Tropical, 33: 83-87. Disponível em: <http://www.redalyc.org/pdf/2530/253021544005.pdf.> [Acesso em: 17.iv.2018].

Stüpp, J.J., M.I.C. Boff \& P.A.S. Gonçalves, 2006. Manejo de Diabrotica speciosa com atrativos naturais em horta orgânica. Horticultura Brasileira, 24: 442-445. DOI: https://doi.org/10.1590/s0102-05362006000400009.

Vendramim, J.D. \& E. Castiglioni, 2000. Aleloquimicos, resistência de plantas e plantas inseticidas, p. 113-128. In: Guedes, J.C., I.D. Costa \& E. Castiglioni (Orgs). Bases e técnicas do manejo de insetos. Santa Maria: Palloti, 248 p.

\section{Suggestion citation:}

Milléo, J., C.H. Antunes, E.B. Pettres, R.A. Ayub \& P.V. Farago, 2019. Óleo essencial de citronela (Poaceae) e seus componentes para controle do brasileirinho (Coleoptera: Chrysomelidae) em olerícolas. EntomoBrasilis, 12 (1): 06-10.

Available on: doi:10.12741/ebrasilis.v12i1.782
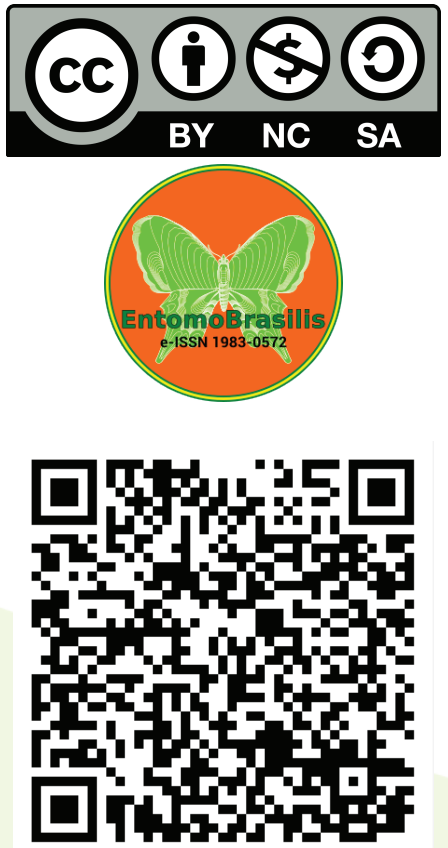